Wang Xin, Li Shuli, Yang Liguo*, Tian Dayong and Niu Yongsheng

\title{
The crystal structure of (E)-5-chloro-2-hydroxy- $N^{\prime}-$ (2-hydroxy-4-methoxybenzylidene) benzohydrazide, $\mathrm{C}_{15} \mathrm{H}_{13} \mathrm{ClN}_{2} \mathrm{O}_{4}$
}

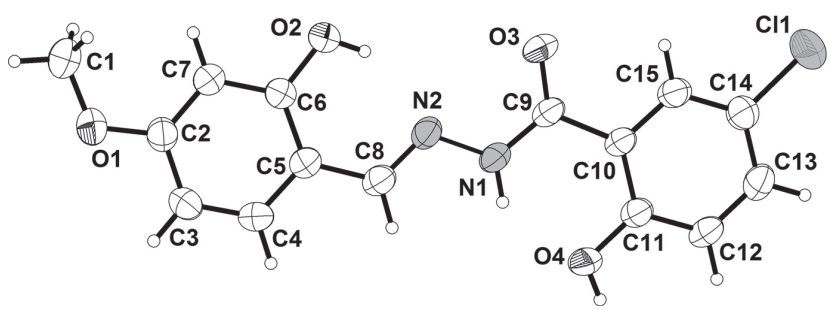

https://doi.org/10.1515/ncrs-2019-0734

Received September 29, 2019; accepted December 20, 2019; available online January 25,2020

Table 1: Data collection and handling.

\begin{tabular}{ll}
\hline Crystal: & Colorless block \\
Size: & $0.08 \times 0.06 \times 0.04 \mathrm{~mm}$ \\
Wavelength: & Mo $K \alpha$ radiation $(0.71073 \AA)$ \\
$\mu:$ & $0.29 \mathrm{~mm}^{-1}$ \\
Diffractometer, scan mode: & Bruker APEX-II, $\varphi$ and $\omega$-scans \\
$\theta_{\text {max }}$, completeness: & $27.1^{\circ},>99 \%$ \\
$N(h k l)_{\text {measured }}, N(h k l)_{\text {unique }}, R_{\text {int }}:$ & $16118,3329,0.028$ \\
Criterion for $I_{\text {obs }}, N(h k l)_{\mathrm{gt}}:$ & $I_{\text {obs }}>2 \sigma\left(I_{\text {obs }}\right), 2608$ \\
$N(\text { param })_{\text {refined }}:$ & 202 \\
Programs: & Bruker programs [1], SHELX [2, 3]
\end{tabular}

\begin{abstract}
$\mathrm{C}_{15} \mathrm{H}_{13} \mathrm{ClN}_{2} \mathrm{O}_{4}$, monoclinic, $P 2_{1} / c$ (no. 14), $a=16.632(2) \AA$, $b=7.2033(9) \AA, \quad c=12.9261(17) \AA, \quad \beta=112.87^{\circ}$, $V=1427.0(3) \AA^{3}, Z=4, R_{\mathrm{gt}}(F)=0.0409, w R_{\text {ref }}\left(F^{2}\right)=0.1260$, $T=296(2) \mathrm{K}$.
\end{abstract}

\section{CCDC no.: 1973252}

The crystal structure is shown in the figure. Table 1 contains crystallographic data and Table 2 contains the list of the atoms including atomic coordinates and displacement parameters.

\section{Source of material}

A mixture of 2-hydroxy-5-chlorobenzohydrazide (0.186 g, $1 \mathrm{mmol}$ ) and 2-hydroxy-4-methoxybenzaldehyde (0.152 g, $1 \mathrm{mmol}$ ) in $50 \mathrm{~mL}$ methanol was stirred at room temperature for $1 \mathrm{~h}$. The mixture was filtered to remove impurties, and then left at room temperature. After a few days, colourless blocks of the title compound formed. Yield (0.25 g, 80\%).

*Corresponding author: Yang Liguo, College of Chemistry and Environmental Engineering, Anyang Institute of Technology, Anyang 455000, Henan, P.R. China, e-mail: Igyang@ayit.edu.cn. https://orcid.org/0000-0003-4899-8298

Wang Xin, Li Shuli, Tian Dayong and Niu Yongsheng: College of Chemistry and Environmental Engineering, Anyang Institute of Technology, Anyang 455000, Henan, P.R. China
Table 2: Fractional atomic coordinates and isotropic or equivalent isotropic displacement parameters $\left(\AA^{2}\right)$.

\begin{tabular}{lrrrr}
\hline Atom & $\boldsymbol{x}$ & $\boldsymbol{y}$ & $\boldsymbol{z}$ & $\boldsymbol{U}_{\text {iso }}{ }^{*} \boldsymbol{U}_{\text {eq }}$ \\
\hline O1 & $0.89078(7)$ & $0.0820(2)$ & $0.89053(10)$ & $0.0556(3)$ \\
O2 & $0.58815(7)$ & $0.2280(2)$ & $0.73958(10)$ & $0.0575(4)$ \\
H2 & 0.5472 & 0.2414 & 0.6790 & $0.086^{*}$ \\
O3 & $0.35144(8)$ & $0.36938(19)$ & $0.49349(8)$ & $0.0506(3)$ \\
O4 & $0.37832(7)$ & $0.26592(19)$ & $0.19203(9)$ & $0.0493(3)$ \\
H4A & 0.3720 & 0.2315 & 0.1289 & $0.074^{*}$ \\
N1 & $0.44313(8)$ & $0.28060(19)$ & $0.41359(10)$ & $0.0413(3)$ \\
H1 & 0.4514 & 0.2631 & 0.3527 & $0.050^{*}$ \\
N2 & $0.51065(8)$ & $0.25111(19)$ & $0.51683(10)$ & $0.0402(3)$ \\
Cl1 & $0.04256(3)$ & $0.48559(9)$ & $0.19785(4)$ & $0.0736(2)$ \\
C1 & $0.89702(12)$ & $0.1094(3)$ & $1.00140(15)$ & $0.0619(5)$ \\
H1A & 0.8804 & 0.2344 & 1.0096 & $0.093^{*}$ \\
H1B & 0.9560 & 0.0882 & 1.0528 & $0.093^{*}$ \\
H1C & 0.8589 & 0.0243 & 1.0172 & $0.093^{*}$ \\
C2 & $0.81249(10)$ & $0.1099(2)$ & $0.80400(13)$ & $0.0414(3)$ \\
C3 & $0.81304(11)$ & $0.0923(3)$ & $0.69732(14)$ & $0.0479(4)$ \\
H3 & 0.8643 & 0.0609 & 0.6885 & $0.057^{*}$ \\
C4 & $0.73774(11)$ & $0.1216(2)$ & $0.60519(13)$ & $0.0449(4)$ \\
H4 & 0.7389 & 0.1099 & 0.5341 & $0.054^{*}$ \\
C5 & $0.65970(10)$ & $0.1681(2)$ & $0.61405(12)$ & $0.0368(3)$ \\
C6 & $0.66038(9)$ & $0.1833(2)$ & $0.72224(12)$ & $0.0386(3)$ \\
C7 & $0.73652(10)$ & $0.1529(2)$ & $0.81666(13)$ & $0.0418(4)$ \\
H7 & 0.7358 & 0.1616 & 0.8881 & $0.050^{*}$ \\
C8 & $0.58319(10)$ & $0.2030(2)$ & $0.51312(12)$ & $0.0406(3)$ \\
H8 & 0.5871 & 0.1900 & 0.4436 & $0.049^{*}$ \\
C9 & $0.36536(10)$ & $0.3362(2)$ & $0.40889(11)$ & $0.0367(3)$ \\
C10 & $0.29387(9)$ & $0.3547(2)$ & $0.29488(11)$ & $0.0344(3)$ \\
C11 & $0.30008(9)$ & $0.3148(2)$ & $0.19265(12)$ & $0.0369(3)$ \\
C12 & $0.22591(11)$ & $0.3265(2)$ & $0.09316(12)$ & $0.0429(4)$ \\
& & & &
\end{tabular}


Table 2 (continued)

\begin{tabular}{lrrrr}
\hline Atom & $\boldsymbol{x}$ & $\boldsymbol{y}$ & $\boldsymbol{z}$ & $\boldsymbol{U}_{\text {iso }} \boldsymbol{U}_{\text {eq }}$ \\
\hline $\mathrm{H} 12$ & 0.2304 & 0.2998 & 0.0252 & $0.052^{\star}$ \\
$\mathrm{C} 13$ & $0.14659(10)$ & $0.3766(2)$ & $0.09375(13)$ & $0.0460(4)$ \\
$\mathrm{H} 13$ & 0.0973 & 0.3820 & 0.0272 & $0.055^{*}$ \\
$\mathrm{C} 14$ & $0.14129(10)$ & $0.4187(2)$ & $0.19461(13)$ & $0.0437(4)$ \\
$\mathrm{C} 15$ & $0.21367(10)$ & $0.4080(2)$ & $0.29366(12)$ & $0.0405(3)$ \\
$\mathrm{H} 15$ & 0.2085 & 0.4372 & 0.3609 & $0.049 *$ \\
\hline
\end{tabular}

\section{Experimental details}

Atoms were geometrically placed $(\mathrm{C}-\mathrm{H}=0.95-0.98 \AA)$ and refined as riding with $U_{\text {iso }}(\mathrm{H})=1.2-1.5 U_{\text {eq }}$ (parent atom) [1-3].

\section{Discussion}

Schiff bases show interesting properties due to o-hydroxy group forming intra-molecular hydrogen bonds. The hydrazones may act as an efficient chelating ligand, which coordinate with varous transition metals. Some complexes containing the hydrazones ligand have been repored [4-6]. Schiff base complexes are attracting considerable attention in several different fields ranging from bioinorganic chemistry to solid-state physics. Low-nuclearity species have been extensively studied as models for the water oxidizing complex in photosystem II, whereas nanometer-size clusters with high-spin ground states are currently being investigated as single-molecule magnets. However, to the best of our knowledge, the ligand has not been reported. The similar structure has been reported [7].

As shown in the figure, the title compound crystallizes in the monoclinic space group $P 2_{1} / c$ with one molecule in the asymmetric unit. The bond lengths of $\mathrm{N} 2=\mathrm{C} 8, \mathrm{~N} 1-\mathrm{C}$, C14-Cl1 and N2-N1 are 1.274, 1.333, 1.727 and $1.386 \AA$ A, respectively, which are similar with the directly related structures. The atoms 02, 03, N2, are the coordination atoms of the ligand, one ligand will coordinate with three metal atoms. The transition metal complexes have been reported, but the rare earth metal complexes have not been reported, our group will do this job in the future. This sentence was added after [7-16].

Acknowledgements: The authors gratefully acknowledge scientific and technological project of Henan province (192102310232), the Anyang Key Laboratory for Chemical Biosensing (21302003), and Key discipline of environmental engineer of Anyang Institute of Technology the Natural Science Foundation of China (21471015, 21631003, 21561007, and 21701046), the Innovation Program for High-level Talents of Guizhou Province (No. 2016-5657), the Science and Technology Fund of Guizhou Province (No. 2016-1030), the Major
Program for Creative Research Groups of Guizhou Provincial Education Department (2017-028), and the Fundamental Research Funds for the Central Universities (FRF-BD-17-016A).

\section{References}

1. Bruker: APEX3, SAINT-Plus, XPREP. Bruker AXS Inc., Madison, WI, USA (2016).

2. Sheldrick, G. M.: SHELXT - Integrated space-group and crystal-structure determination. Acta Crystallogr. A71 (2015) 3-8.

3. Sheldrick, G. M.: Crystal structure refinement with SHELXL. Acta Crystallogr. C71 (2015) 3-8.

4. Thompsom, L. K.; Matthews, C. J.; Zhao, L.; Claire, W.; Leech, M. A.; Howard, J. A. K.; Katsuki, T.: Supramolecular metal helicate structures with incomplete metal ion coordination. J. Chem. Soc. Dalton. Trans. 15 (2001) 2258-2262.

5. Niel, V.; Milway, V. A.; Dawe, L. N.; Grove, H.; Tandon, S. S.; Abedin, T. S. M.; Kelly, T. L.; Spencer, E. C.; Howard, J. A. K.; Collins, J. L.; Miller, D. O.: Coordination oligomers in selfassembly reactions of some tritopic picolinic dihydrazone ligandss mononuclear, dinuclear, hexanuclear, heptanuclear, and nonanuclear examples. Inorg. Chem. 47 (2008) 176-189.

6. Zhao, L.; Xu, Z. Q.; Grove, H.; Milway, V. A.; Dawe, L. N.; Abedin, T. S. M.; Thompson, L. K.; Kelly, T. L.; Harvey, R. G.; Miller, D. O.; Weeks, L.; Shapter, J. G.; Pope, K. J.: Supramolecular Mn(II) and $\mathrm{Mn}(\mathrm{II}) / \mathrm{Mn}(\mathrm{III})$ grid complexes with $\left[\mathrm{Mn}_{9}\left(\mu_{2}-0\right)_{12}\right]$ core structures. Structural, magnetic, and redox properties and surface studies. Inorg. Chem. 43 (2004) 3812-3824.

7. Han, Y. Y.; Zhao, Q. R.: N'-(2-Chlorobenzylidene)-2-hydroxy-3methylbenzohydrazide. Acta. Crystallogr. E66 (2010) 01025.

8. Yuan, J.; Xing, A.-P.; Cheng, D.: Crystal structure of 2-hydroxy$N^{\prime}$-(pyrimidin-2-yl)benzohydrazide, $\mathrm{C}_{11} \mathrm{H}_{10} \mathrm{~N}_{4} \mathrm{O}_{2}$. Z. Kristallogr. NCS 233 (2018) 817-818.

9. Barbazán, P.; Carballo, R.; Vázquez-López, E. M.: Synthesis and structure of 2-acetylpyridine-salicyloylhydrazone and its copper(II) and zinc(II) complexes. The effect of the metal coordination on the weak intermolecular interactions. CrystEngComm 9 (2007) 668-675.

10. Addison, A. W.; Rao, T. N.; Reedijk, J.; van Rijn, J.; Verschoor, G. C.: Synthesis, structure, and spectroscopic properties of copper(II) compounds containing nitrogen-sulphur donor ligands; the crystal and molecular structure of aqua [1,7-bis ( $N$-methylbenzimidazol-2'-yl)-2,6-dithiaheptane] copper(II) perchlorate. J. Chem. Soc. Dalton Trans. 7 (1984) 1349-1356.

11. Karmakar, R.; Choudhury, C. R.; Batsanov, A. S.; Batten S. R.; Mitra, S.: Synthesis and structural characterisation of two copper(II) complexes of $N$-(1-acetyl-2-propylidene)(2pyridylmethyl) amine. Struct. Chem. 16 (2005) 535-539.

12. Waldmann, O.; Zhao, L.; Thompson, L. K.: Field-dependent anisotropy change in a supramolecular $\mathrm{Mn}(\mathrm{II})$-[3 $\times 3]$ grid. Chem. Phys. Lett. 88 (2002) 066401.

13. Zhao, L.; Xu, Z.; Thompson, L. K.; Miller, D. O.: Self assembled polynuclear [3×3] grids - structural and magnetic properties of $\mathrm{Mn}(\mathrm{II}), \mathrm{Fe}(\mathrm{III}), \mathrm{Co}(\mathrm{II}), \mathrm{Ni}(\mathrm{II})$ and $\mathrm{Cu}(\mathrm{II})$ complexes with $M_{9}\left(\mu_{2}-0\right)_{12}$ cores. Polyhedron 20 (2001) 1359-1364.

14. Dawe, L. N.; Abedin, T. S. M.; Kelly, T. L.; Thompson, L. K.; Miller, D. O.; Zhao, L.; Wilson, C.; Leech, M. A.; Howard, J. A. K.: Self-assembled polymetallic square grids $\left([2 \times 2] M_{4}\right.$, 
[3 $\left.\times 3] M_{9}\right)$ and trigonal bipyramidal clusters $\left(M_{5}\right)$-structural and magnetic properties. J. Mater. Chem. 16 (2006) 2645-2659.

15. Thompson, L. K.; Zhao, L.; Xu, Z.; Miller, D. O.; Reiff, W. M.: Self-assembled supramolecular $M_{9}$ (Mn(II), $\mathrm{Fe}(\mathrm{III}), \mathrm{Zn}(\mathrm{II})$ ), $\mathrm{M}_{5}$
(Fe(III)), and $\left[\mathrm{M}_{3}\right]_{2}(\mathrm{~Pb}(\mathrm{II}))$ complexes: structural, magnetic, and mössbauer properties. Inorg. Chem. 42 (2003) 128-139.

16. Milway, V. A.; Thompson, L. K.; Miller, D. O.: Self-assembly by ligand disassembly?-formation of an unusual dodecanuclear [Co(ii) $\left.{ }_{6} \mathrm{Co}(\mathrm{iii})_{6}\right]$ cluster. Chem. Commun. 16 (2004) 1790-1791. 